\title{
SEGMENT PROFITABILITY IN THE LEISURE INDUSTRY
}

Rainer Lueg, Leuphana University, Germany and University of Southern Denmark, Denmark

\author{
dx.doi.org/10.18374/IJBS-21-1.2
}

\begin{abstract}
This case study illustrates a young franchise in the leisure industry on its path to higher profitability. Specifically, it deals with the profitability of its different recreational segments and the profitability of the main customer groups within these segments. It also discusses how to incentivize non-executive, regular employees to improve the profitability of segments and customer groups. In addition, it also elaborates which control mechanisms of top management are appropriate to monitor the progress. The open questions at the end of the case study should foster classroom discussions on managerial implications.
\end{abstract}

Keywords: Segment profitability; customer profitability; teaching notes; target setting; incentives. 